\title{
Hacia una correcta delimitación de las libertades negativas en el contexto neoliberal.
}

\section{Towards a correct delimitation of negative freedoms in the neoliberal context.}

DOI: $10.32870 /$ sincronia.axxv.n80.25b21

\author{
Sissi Cano Cabildo \\ Facultad de Filosofía, Universidad Complutense de Madrid. (ESPAÑA).
}

CE: sicano@ucm.es / ID ORCID: 0000-0001-9604-3109

Esta obra está bajo una Licencia Creative Commons Atribución-NoComercial 4.0 Internacional

Recibido: 04/03/2021

Revisado: 25/04/2021

Aprobado: 16/06/2021

\section{RESUMEN}

En este trabajo propongo analizar cuáles serían los límites correctos de las libertades negativas para reconstruir nuestra cultura cívica desde el respeto, el reconocimiento, la justicia y la responsabilidad ecológica. A lo largo de la historia habíamos visto muchas formas de gobierno dictatoriales donde no había margen para la libertad mientras que actualmente estamos viendo en el contexto neoliberal prácticamente lo contrario, la legitimación de las libertades negativas ilimitadas, sobre todo en lo que concierne a la libertad de expresión y de la propiedad privada, deviniendo en un individualismo rapaz que subestima el respeto, la justicia y los derechos de los demás. No es poca cosa...

Palabras clave: Libertades negativas. Límites. Pensamiento. Respeto y justicia. 


\section{ABSTRACT}

Towards a correct delimitation of negative freedoms in the neoliberal context In this work I propose to analyze what would be the correct limits of negative freedoms to reconstruct our civic culture based on respect, recognition, justice and ecological responsibility. Throughout history we had seen many dictatorial forms of government where there was no margin for freedom while we are currently seeing in the neoliberal context practically the opposite, the legitimation of unlimited negative freedoms, especially with regard to freedom of expression and private property, resulting in a rapacious individualism that underestimates respect, justice and rights of others. It is no small thing...

Key words: Negative freedoms. Limits. Thought. Respect and justice.

\section{Introducción}

Uno de los conceptos que siempre ha estado presente en la disertación filosófica ha sido el de la libertad y no es para menos si pensamos que la existencia humana siempre ha sido un continuo proceso de deliberaciones y decisiones que finalmente nos llevan a pensar en la libertad. No obstante, a lo largo de la historia podemos ver que la libertad ha sido un concepto polisémico, sea por los distintos contextos en donde ha surgido, distintos idiomas y filtros hermenéuticos. El discurso filosófico no es la excepción, tenemos diferentes concepciones de la libertad en las distintas corrientes filosóficas como el teleologismo, la filosofía cristiana, la ilustración, el liberalismo, el existencialismo, etc. De ahí el empeño de algunos grandes pensadores por esclarecer y esquematizar los principales enfoques de la libertad, tenemos por ejemplo el clásico de Constant "De la libertad de los antiguos comparada con la libertad de los modernos" (2002), el enfoque de la libertad positiva y negativa de Isaiah Berlin, la distinción arendtiana entre libertad filosófica, liberación y libertad política, la libertad como "no dominación" de Pettit, Skinner y MacCallum, entre otros. 
En este artículo analizaré el sentido de las libertades negativas (Berlin, 2008) ante la problemática actual y a partir de ello dejar ver la estrechez moral del enfoque neoliberal de la libertad. Obviamente no abarcaré todo lo que engloba el concepto "neoliberalismo" (que dicho sea de paso sería imposible agotarlo en 30 páginas) sino solamente me centraré en analizar el sentido de la libertad que postula el enfoque neoliberal. Me referiré al neoliberalismo como al período capitalista postkeynesiano, que se construye desde el discurso hegemónico que sustenta la libertad individual y el derecho ilimitado a la propiedad privada, a partir de lo cual se legitima el proceso de liberalización de la economía, privatización, financiarización, una drástica reducción del gasto público y de la intervención del Estado a favor del sector privado (Harvey, 2007).

Las libertades negativas se refieren al "poder hacer" del individuo ante la presión/opresión de los demás y el "neoliberalismo" pareciera asumir que estas libertades individuales deben ser ilimitadas, sobre todo en lo que respecta a la libertad de expresión y a la propiedad privada, deviniendo en una suerte de individualismo rapaz que demerita el sentido humanista de la libertad que originalmente defendió el liberalismo clásico, que pensaba en la libertad de todos y por ello evocaba los límites correctos de las libertades individuales.

Ahora bien, se podría pensar que este ejercicio de disertación filosófica sobre el declive del sentido de la libertad sea solo una pretensión semántica irrelevante pero quizá sea más bien un primer paso para asumir la responsabilidad y el empoderamiento consecuente de la libertad. Recordemos de Berlin:

[...] Heine advirtió a los franceses que no subestimaran el poder de las ideas; los conceptos filosóficos criados en la quietud del cuarto de estudio de un profesor podían destruir una civilización. Él hablaba de la Crítica de la razón pura de Kant, como la espada con que había sido decapitado el deísmo europeo; describía a las obras de Rousseau como el arma ensangrentada que en manos de Robespierre había destruido el antiguo régimen [...]. Puede ser que las ideas políticas sean algo muerto sino cuentan con la presión de las fuerzas sociales, pero lo que es cierto es que estas fuerzas son ciegas y carecen de dirección si no se revisten de ideas. (Berlin, 1988, pp. 216-217). 


\section{Seguimiento histórico de las libertades negativas}

Las libertades negativas corresponden a la ausencia de coerción para realizar los deseos individuales y así fue planteado por Isaiah Berlin:

Llamaré su sentido negativo al que contesta a la pregunta por el ámbito en que al sujeto se le deja o se le debe dejar hacer o ser lo que es capaz de hacer o ser, sin que en ello interfieran otras personas. (Berlin, 1988, p.40).

Este margen de acción que garantiza cierta libertad depende de los demás, sea la pareja, la familia, la sociedad, las instituciones religiosas o el estado; pero como el margen de acción nunca es ilimitado, se entiende que este enfoque sea negativo porque siempre hay límites y condiciones por parte del contexto y de la situación.

Ahora bien, justamente por este sentido negativo de la libertad se podría pensar que la libertad no existe pues sería una incongruencia semántica hablar de "libertad limitada" o "libertad condicionada" y no falta razón en este planteamiento, así que este sentido de la libertad es un tanto débil y negativo pero real; de hecho, las libertades sociales y jurídicas se limitan desde la negatividad exógena. No obstante, para evitar objeciones de orden lingüístico, más que hablar de libertad limitada, Berlin habla de libertad negativa cuando se refiere a este sentido menos estricto pero funcional en el uso cotidiano y en la normatividad jurídica. Por el contrario, Berlin habla de libertad positiva para referirse a otro sentido de la libertad propiamente ontológico, que apunta a la posibilidad de la autodeterminación de la voluntad, que trasciende cualquier forma de determinismo; pero este sentido de la libertad es harto complejo y profundo que desviaría justificadamente el tema central de este artículo.

El enfoque negativo de la libertad no se refiere a la libertad positiva interior, sino que se refiere a las acciones, sólo alude a las posibilidades que tenemos de hacer lo que queramos y que efectivamente podemos hacer. Alguien podría decir por ejemplo, que se casó libremente en cuanto 
que nadie le impidió ni le obligó a casarse, pero desde este planteamiento nada se dice de la libertad positiva, de las motivaciones o causas que llevaron a dicho sujeto a tomar esa decisión, si fue por algún motivo oculto en el entramado del determinismo inconsciente, familiar, neurológico o histórico.

El sentido negativo de la libertad tuvo su primera fundamentación filosófica en la magna Grecia, posteriormente defendida por Hobbes y sobre todo por el liberalismo clásico como veremos más adelante.

Desde la perspectiva griega del cosmos, se concebía al mundo como el conjunto de seres interconectados causalmente y por tanto, en interdependencia racional; incluso el ser humano como parte del cosmos no podía autodeterminarse espontánea e independientemente de la lógica del mundo, podía ignorarla pero no sustraerse a ella. Así, había margen para la ignorancia pero no para la irracionalidad. Cuando los griegos hablaban de hombres libres se referían a la libertad en un sentido negativo, para referirse a aquellas personas que podían hacer lo que quisiesen, a diferencia de los esclavos o de las mujeres. Los hombres eran considerados libres en tanto que no tenían la obligación de obedecer pero tampoco de mandar y en ese sentido eran independientes, no dependían de horarios ni de alguien en particular. Pero también es cierto que muy pocos gozaban de esas libertades negativas.

Las libertades civiles como derechos de todos los seres humanos fueron desconocidas por las civilizaciones antiguas. Entre los judíos, chinos, griegos, romanos y todas las civilizaciones antiguas, como dice Condorcet, no existió noción alguna de los derechos individuales. Lo que los antiguos entendían por libertad era compatible con la sujeción completa del individuo a la autoridad de la multitud reunida. Terpandro no pudo entre los espartanos añadir una cuerda a su lira sin que los éforos se diesen por ofendidos. Vemos también que un joven lacedemonio no podía visitar libremente a su nueva esposa. En Roma, los censores escudriñaban hasta el interior de las familias pues las leyes regulaban las costumbres. Autores como Hannah Arendt, Ryle, Hartmann, Wilson y Berlin coinciden en considerar que el enfoque de la libertad individual y autorreferencial fue desconocido en la Grecia Clásica. Cito de La vida del espíritu: 
Cualesquiera que sean los méritos de las teorías posteriores a la antigüedad que sitúan la libertad humana en el yo quiero, lo cierto es que en el marco del pensamiento precristiano estaba situada en el yo puedo; la libertad era un estado objetivo del cuerpo y no un datum de la conciencia o del espíritu. La libertad significaba que uno podía hacer lo que gustase, sin verse constreñido por las órdenes de un amo, ni por alguna necesidad física que exigiera trabajar por un salario por el fin de alimentar el cuerpo, ni por algún inconveniente somático tal como una enfermedad o una parálisis. Según la etimología griega, es decir, de acuerdo con la interpretación que hacían los griegos, la raíz de la palabra 'libertad', eleutheria es 'ir al aire que se desee', no cabe duda de que la libertad básica era entendida como libertad de movimiento. Una persona era libre si podía moverse como gustase; el criterio era el yopuedo, y no el yo-quiero. (Arendt, 2002, p. 252).

La libertad en Grecia también tenía una connotación política, como participación pública, propia de los ciudadanos; sólo que la ciudadanía era un derecho excluyente, no todos podían acceder a ella; de hecho la mayoría de los habitantes de la polis no eran libres, muy pocos eran los que podían participar políticamente. Llevó muchos siglos poder ver a la libertad política como un derecho de todos, si incluso todavía hay mucho por hacer al respecto... el proceso de empoderamiento de la ciudadanía ha tenido que vencer muchos prejuicios sexistas, racistas, religiosos y clasistas.

Ya en la época medieval, pese a la propuesta filosófica de la libertad cristiana, lo que realmente se llevó a cabo, fueron las libertades del clero y los privilegios heredados junto con el título y la tierra. La función de las leyes era básicamente proteger la propiedad, pues era la propiedad y el estatus lo que garantizaban la "libertad" como poder de acción y de participación.

Ya en el s. XVII encontramos el planteamiento teórico de la libertad negativa en el iusnaturalismo de Hobbes: "por libertad se entiende, de acuerdo al significado propio de la palabra, la ausencia de impedimentos externos, impedimentos que con frecuencia reducen parte del poder que un hombre tiene de hacer lo que quiere". (2017, p. 97). No obstante, este planteamiento no devino en promoción y ampliación de las libertades individuales, muy por el contrario devino en la postulación de un Estado total, dado que Hobbes concebía al ser humano como egoísta por 
naturaleza, consideraba que los hombres eran capaces de ceder parte de su libertad al soberano con tal de sobrevivir. Desde este planteamiento se entendía que la razón permite entender y aceptar que debe haber un poder suficientemente fuerte para poner orden y garantizar la sobrevivencia de todos.

El proceso de empoderamiento de las libertades negativas a lo largo de la historia ha sido muy lento y penoso; aún en la actualidad tenemos mucho que hacer al respecto, por un lado hacer extensivas las libertades a grupos vulnerables y excluidos pero también replantear los límites correctos de esas libertades. Las libertades que el gobierno constitucional garantiza tienen todas un carácter negativo, así Berlin cita de Bentham que "toda ley es una infracción de la libertad" (Isaiah, 1988, p. 57) en cuanto que coaccionan y protegen de los abusos de la libertad. Los límites a las libertades son para proteger a la libertad misma, no olvidemos que la libertad de los fuertes generalmente ha llevado a la opresión de los débiles; de manera que resulta necesario postular mecanismos institucionales que protejan la libertad de todos.

El liberalismo será la corriente filosófica que propiamente sustente la libertad como el eje de su argumentación y de su propuesta politológica, no en vano se llama así; sólo que la libertad que postula es sobre todo en su sentido negativo. John Stuart Mill justamente empieza la introducción de su emblemática obra Sobre la libertad diciendo:

El objeto de este ensayo no es lo que se ha dado en llamar el libre arbitrio, con tan escasa fortuna opuesto a la denominada con impropiedad doctrina de la necesidad filosófica, sino la libertad civil o social, es decir, la naturaleza y los límites del poder que la sociedad puede ejercer legítimamente sobre el individuo. (Stuart, 2017, p.37).

Esto es, que John Stuart Mill deja ver desde el inicio de su obra que no va a disertar sobre el enfoque ético y metafísico de la libertad, no va a analizar si la voluntad humana está determinada o no; sino que va a analizar los límites que deben tener las libertades individuales en sociedad. Y este tema no es poca cosa, muy por el contrario puede ser una de las más grandes aportaciones de la modernidad, justamente porque dio pauta al reconocimiento y protección jurídica de nuestra 
individualidad, a ser únicos y distintos a los demás; pero también a respetar la libertad de los demás y por lo tanto, la pluralidad consecuente.

Y me interesa replantear este último punto a propósito del enfoque neoliberal porque me parece que se han desvirtuado las libertades individuales, deviniendo en alguna suerte de relativismo anárquico, creyendo que las libertades individuales por sí mismas no deben tener límites, como si fuera legítimo evocar la propia libertad en menoscabo de la libertad de los demás. En otros términos, que en el contexto neoliberal se tiende a creer que la libertad de expresión, de asociación, de prensa y de credo no tienen por qué considerar el respeto a los demás como si esto fuera un prejuicio moralista premoderno y represor. Retomo de John Stuart Mill una reflexión demoledora:

La única libertad que merece tal nombre es la de buscar nuestro propio bien por nuestro propio camino, en tanto no tratemos de privar a los demás del suyo o dificultemos sus esfuerzos por conseguirlo. [...] La humanidad sale más beneficiada si se consciente que cada cual viva a su manera que si se ve obligado a vivir como les parece bien a los demás. (Stuart, 2017, p. 58).

El liberalismo del s. XX seguirá defendiendo este sentido de la libertad y así lo vemos en Berlin y Rawls principalmente, pero con la crisis del estado keynesiano se empezó a mercantilizar el sentido de la libertad, centrándose más que nada en la liberalización económica y en el derecho de la propiedad privada ilimitada. Pensemos más detenidamente en ello...

\section{Libertad de pensamiento}

El primer escalón para comprender y valorar el sentido de la libertad es sin lugar a dudas atreverse a pensar. Y aunque la libertad de pensamiento no es propiamente una libertad negativa, sí que es su antesala porque de lo que pensemos y de lo que no pensemos derivarán nuestras acciones. Stuart Mill como buen liberal reivindicaba la libertad de pensamiento para ejercer correctamente la propia libertad. Tiempo después Emilio Lledó dijo en una entrevista: “Lo que hay que tener, principal y 
primariamente, es libertad de pensamiento. ¿Qué me importa a mí la libertad de expresión si no digo más que imbecilidades?" (2013).

De hecho, todos los grandes pensadores muestran y demuestran la importancia del pensamiento (Denken), sólo que algunos como Hannah Arendt lo reivindican para efectos éticopolíticos en cuanto que nos puede prevenir de cualquier tipo de manipulación perniciosa para uno mismo y para los demás:

Si el pensar -el dos en uno del diálogo silencioso- [...] La manifestación del viento del pensar no es el conocimiento; es la capacidad de distinguir lo bueno de lo malo, lo bello de lo feo. Y esto, en los raros momentos en que se ha alcanzado un punto crítico, puede prevenir catástrofes, al menos para mí (Arendt, 2002, p. 215).

Arendt analizó los peligros de la irreflexión a partir del seguimiento del caso Eichmann, uno de los principales responsables del holocausto y que en el juicio asumió una actitud irresponsable, sin algún sentimiento de culpa o de arrepentimiento. En el juicio como teniente coronel de las SS nunca expuso argumentos o criterios personales que explicaran su conducta, sino que tendía a repetir clisés o slogans, frases pegadizas que llamaba "palabras aladas", lo que dejaba ver su adoctrinamiento; su evidente gusto por palabras rimbombantes le hicieron un sujeto ideal para el empleo del "lenguaje en clave" y su reiterada afasia le llevaron a disculparse frecuentemente diciendo: “mi único lenguaje es el burocrático" (Arendt, 1999, p. 79). Ahora bien, Eichmann no tenía el perfil psicológico de psicópata, seis psiquiatras certificaron que era un hombre "normal", incluso uno de ellos consideró que los rasgos psicológicos de Eichmann hacia su familia y amigos eran no sólo normales, sino ejemplares. De lo que Arendt comenta que lo propio de este personaje fue más bien la irreflexión pero no porque careciera de la facultad de pensar sino por su apatía y conformismo de burócrata acomodaticio. De donde se perfiló algo aterrador: que para hacer daño no hacen falta malas intenciones, se pueden cometer atrocidades desde la vil estupidez, dejando ver que la falta de pensamiento puede tener entonces graves consecuencias sociales y políticas. 
El pensamiento no se construye desde la intersubjetividad sino que es sumamente personal, es autorreflexión; se mueve entre universales y esencias invisibles, no produce resultados concretos, es fuente incesante de preguntas sin respuestas. Esta capacidad no descubrirá de una vez por todas lo que sea el bien y el mal, ni proporciona algún mandato o proposición moral, no confirma, más bien disuelve las reglas de conducta establecidas; pero entonces ¿para qué sirve? Que el pensamiento o los grandes pensadores no puedan dar respuestas absolutas a los principales cuestionamientos humanos pudiera desanimar cualquier búsqueda al respecto y sin embargo, Arendt considera que ahí está justamente el encanto, la riqueza y la creatividad de la vida humana; incluso va más lejos al considerar pedantes y peligrosas a los pilares de la verdad (Dios, el progreso, el honor, la nación, etc.) si muchos de ellos han legitimado injusticias, muertes y guerras, decía que "los errores más terribles han sustituido a las verdades más conocidas" (Arendt, 2001, p.21). No queda más que pensar y repensar lo establecido, asumir una actitud crítica no es poca cosa, muy por el contrario puede que sea el único recurso que nos quede para afrontar el bombardeo de información de las telecomunicaciones y de cualquier manipulación telemática, religiosa, sexual, política o de cualquier tipo. Si vamos a defender la libertad, que sea desde el pensamiento y no desde la insensatez, veámoslo con más detenimiento...

\section{Libertad de expresión, respeto y tolerancia}

En este apartado pretendo dejar ver la pertinencia de replantear los límites de las libertades sociales y jurídicas a propósito del respeto a los demás, sobre todo en nuestro contexto multicultural donde pareciera fácil perderse en relativismos o bien cerrarnos en el etnocentrismo. Sin más preámbulo, desde el relativismo finalmente acabaríamos aceptando todo, donde cualquier expresión sería válida porque se supone que todo depende del cristal con que se mire, y entonces uno creería que la burla y la ofensa son sólo subjetivas; pero la lectura contraria nos conduciría al etnocentrismo y a lecturas monolíticas de la vida, propias de dictaduras y/o fundamentalismos y ya sabemos las consecuencias...

¿Cuál es el punto medio que equilibra las libertades de todos? Si bien es verdad que el estado liberal tiene la función de proteger y garantizar las libertades individuales de la tiranía de la 
sociedad, de la religión o del estado; también es verdad que estas libertades deben ser para todos, no para unos cuantos; de lo contrario se retrocedería a una sociedad estamentaria. Pensando en ello es que apelamos una vez más a los límites correctos que deben tener las libertades individuales de cara al respeto de los demás. La libertad de expresión, de asociación y de culto han sido grandes conquistas de la historia, por las que se han sacrificado muchas personas, ninguno de estos derechos se han conseguido desde la disertación académica; sino que ha habido sangre, sudor y lágrimas de por medio. Assata Shakur decía que: "Nadie en el mundo, nadie en la historia ha conseguido nunca su libertad apelando al sentido moral de sus opresores" (Shakur, 2013, p.48). Así que banalizar la libertad y tergiversar su sentido sería vil ignorancia o suma ingratitud hacia el legado liberal.

La libertad de pensamiento se tendría que replantear ahora más que nunca dado el avance de las telecomunicaciones... Temas como el consumismo, la sexualidad, las adicciones, la violencia y la religión se dan en rienda suelta en las TIC y hemos visto los riesgos que conllevan en cuanto al acoso y la manipulación ideológica, política y religiosa, pero entonces ¿qué es lo correcto? ¿Cuál es el sentido políticamente correcto de la libertad de expresión? ¿En los debates políticos de muchos países prima el respeto? Cuando vemos que en Italia en el 2014, el vicepresidente del Senado, Roberto Calderoli comparó a la ministra de integración Cécile Kyenge con un orangután por sus rasgos fenotípicos africanos, que unos militantes racistas le arrojaron plátanos a la salida de un acto y hubo incluso una consejera municipal que propuso que la violaran para que sufriera en carne propia los crímenes cometidos, supuestamente, por los inmigrantes (Ordaz, 2014). ¿La burla es políticamente correcta? Me parece que este es uno de tantos ejemplos en los que se da uno cuenta que falta educación para la libertad...

Otra cuestión que sale a relucir a propósito de la libertad de expresión es si debe haber límites a lo que podamos decir no solo de las personas sino también de sus símbolos y sus creencias. Un terrible ejemplo muy conocido fue el ataque yihadista a la revista francesa, que para muchos fue un ataque a la libertad de prensa. El lema Je suis Charlie (yo soy Charlie) se propagó por el mundo, mientras que para otros fue la consecuencia predecible de la falta de respeto a las creencias de 
otras personas, escritores de la talla de Peter Carey, Michael Ondaatje, Francine Prose, Teju Cole, Rachel Kushner y Taiye Selas vieron en la publicación una muestra de "intolerancia cultural" (Caballero, 2015). ¿Cuál es el límite de la libertad de expresión en temas religiosos? Viene al caso recordar que el Estado laico se caracteriza por la neutralidad que asume en cuestiones religiosas. El ideal laico quiere unir el pueblo (laos) a partir de un doble fundamento: libertad absoluta de conciencia e igualdad estricta de derechos entre los hombres, cualquiera que sea la opción espiritual que escojan: ser religioso, agnóstico o ateo. El estado laico entonces no es el que impone el ateísmo o alguna confesión religiosa, sino el que se mantiene neutral al respecto, cuando Stalin prohibió la religión en la Unión Soviética entró en contradicción con el laicismo, como lo estuvo Franco imponiendo el catolicismo.

El respeto a los símbolos patrios también es otro tema a debatir, un ejemplo de ello fue la imputación a un presentador de televisión Dani Mateo porque en un programa se sonó la nariz con una bandera de España (Gálvez, 2018). Y podría seguir con muchos más ejemplos que redundarían en evocar cómo hacer compatibles la libertad y el respeto en una sociedad plural. Estos planteamientos de alguna forma ya se habían vislumbrado en el liberalismo clásico, Stuart Mill decía que: "La única parte de la conducta de todo hombre que es responsable ante la sociedad, es aquella que se relaciona con los demás. En lo que sólo concierne a sí mismo su independencia debe ser absoluta" (Stuart, 2017, p. 53).

Pero como decía en la introducción de este artículo mi intención es hacer una llamada de atención para comprender la importancia de clarificar el sentido de la libertad pero sin prescribir cómo ejercerla porque mi objetivo no es moralizar, nada más ajeno a la libertad de los demás; si expongo algunos ejemplos del uso ambiguo de la libertad es solo porque hay que atreverse a exponer estos temas a la crítica y al debate.

A propósito de la libertad inevitablemente sale a relucir el tema del respeto y es que debería ser evidente que en un mundo que compartimos todos, las libertades de los seres humanos sólo pueden coexistir desde el respeto mutuo. Pero una vez más, ¿cuál es el sentido del respeto? Me parece que el respeto parte del reconocimiento de la autonomía y de la libertad de los demás, viene 
del latín respectus: consideración y atención del valor de la otredad. Yo no podría decir que respeto a alguien si paso por alto su voluntad. Ahora bien, cierto es que esa voluntad requiere tener cierto desarrollo mental, supongo que no tengo que explicar que ciertas enfermedades físicas y mentales impiden comprender el sentido del respeto y de la libertad; pero entre personas con edad y salud suficientes para comprender estos temas, sí que hay que imputar la irresponsabilidad de asumir todo esto con moralismos cerrados, candidez inocua, supina soberbia o simplemente por grosería, sin más.

Una cosa es la libertad de expresión como derecho a expresar tu opinión, la denuncia y la crítica con argumentos desde la razonabilidad, el derecho a expresar tus ideas y sentimientos y otra es ofender a las personas y a sus símbolos con palabras o imágenes inmundas. Sostengo sin miedo a caer en moralismos que la libertad de expresión del ciudadano y del artista también tienen límites de cara al respeto de los demás. El respeto es un valor ético-político porque no sólo importo yo sino todos. Y si el respeto es horizontal entonces se podría entender que no hay cabida para la burla y la grosería, a menos que ocurra desde la complicidad, como cuando dos personas bromean porque hay confianza mutua pero es muy distinto a burlarse de alguien sin previo consentimiento.

Y con los símbolos ocurre algo parecido, si pensamos que los símbolos, (sobre todo los que son de orden religioso o patriótico) refieren imágenes que tienen valor sagrado para quienes los representan, se podría entender que los símbolos aluden a la vulnerabilidad de ciertas personas y que por eso mismo nadie debería tener el derecho a prohibir o a burlarse de los sentimientos de nadie, ni a promover símbolos de odio como la esvástica. Una cosa es el derecho a denunciar la corrupción, alguna injusticia o algún delito y otra cosa es arremeter contra los símbolos que representan a muchas otras personas que no tienen que ver con el delito o injusticia cometida. Subestimar los sentimientos y creencias de los demás sería cosificar a la otredad, negar su humanidad, caer en reduccionismos y en lecturas monolíticas que distan mucho del respeto, de la alteridad y comprensión de la pluralidad.

Ahora bien, quizá la comprensión de estos temas sería una pretensión muy alta para el común de los mortales, deseable pero demasiado profunda para las mayorías, esa comprensión que 
Octavio Paz entendía como una suerte de abrazo espiritual. Quizá lo mínimo y elemental que se debe exigir a la ciudadanía es el respeto. Los límites de las libertades negativas estarían marcadas por el respeto, exigible por el propio individuo o en el último caso, por el Estado.

En nuestro contexto multicultural hay gente que piensa que los homosexuales son una falta de respeto a la moral, que criticar al rey es una falta de respeto a España, que hacer caricaturas de Mahoma es una falta de respeto imperdonable, etc., con lo que se dejaría ver que rayamos en el emotivismo relativista que diagnosticaba Maclntyre en la modernidad. Me pregunto entonces si cualquier cosa se debería permitir... supongo que no, hay prácticas que evidentemente atentan contra la integridad del a persona, sea la ablación, los matrimonios concertados o la violencia de género, por ejemplo. Me parece que es de suma pertinencia delimitar el sentido del respeto y de la tolerancia. MacIntyre decía que la tolerancia no es en sí misma una virtud; si es demasiado inclusiva se convierte en vicio. $Y$ es que finalmente la tolerancia por su propio concepto es permisiva y por ello temeraria, si conduce a tolerar cualquier cosa... Conocida es la paradoja de la tolerancia de Karl Popper:

La tolerancia ilimitada debe conducir a la desaparición de la tolerancia. Con este planteamiento no queremos significar, por ejemplo, que siempre debamos impedir la expresión de concepciones filosóficas intolerantes; mientras podamos contrarrestarlas mediante argumentos racionales y mantenerlas en jaque ante la opinión pública, su prohibición sería, por cierto, poco prudente. Pero debemos reclamar el derecho de prohibirlas, si es necesario por la fuerza, pues bien puede suceder que no estén destinadas a imponérsenos en el plano de los argumentos racionales, sino que, por el contrario, comiencen por acusar a todo razonamiento; así, pueden prohibir a sus adeptos, por ejemplo, que prestan oídos a los razonamientos racionales, acusándolos de engañosos, y que les enseñan a responder a los argumentos mediante el uso de los puños o las armas. Deberemos reclamar entonces, en nombre de la tolerancia, el derecho a no tolerar a los intolerantes. Tenemos por tanto que reclamar, en el nombre de tolerancia, el derecho a no tolerar la intolerancia (2010, p. 585). 
John Rawls en un momento dado plantea que una sociedad justa tiene que tolerar al intolerante para no volverse intolerante, y por ello injusta. No obstante, considera que la sociedad tiene un derecho razonable a la supervivencia que prima sobre el principio de tolerancia: "[...] mientras una secta intolerante no sea señalada como intolerante, su libertad únicamente puede ser restringida cuando el tolerante, sinceramente y con razón, cree que su propia seguridad y la de las instituciones de la libertad están en peligro" (Rawls, 1995, p. 202).

Parece dejarse ver entonces que la tolerancia lleva a contradicciones porque finalmente no hay modo de justificar que hay cosas que no se deben tolerar. Además, otro aspecto cuestionable de la tolerancia sería que se asume desde la verticalidad, cambia mucho el enfoque de quien "te tolera" a quien "te respeta". Si la tolerancia acaso tuviera sentido sería en el ámbito privado porque dada la condición humana contingente e imperfecta, podríamos entender que a veces nos equivocamos y que los demás deberían entenderlo en situaciones excepcionales; quizá podríamos comprender una mala contestación del amigo que acaba de perder el trabajo, no es que lo justifiquemos pero quizá sí deberíamos tolerarlo pero otra cosa es el ámbito público, donde los ciudadanos deben tener claro lo que no debemos hacer, ni permitir, sin picaresca.

Al respecto también habría que distinguir la tolerancia de la equidad, en cuanto que ésta última es la justicia aplicada al caso concreto. La equidad (lat. aequitas, aequus, igual) tiene la aspiración de igualdad y por ello en el código penal por ejemplo, se apela a los atenuantes, esto es, a las circunstancias particulares de la responsabilidad criminal que moderan la pena señalada para un delito y que influyen para enjuiciar y penalizar de forma equitativa. Una cosa es el hurto de una anciana enferma en un supermercado y otra la estafa de cualquier político; en este ejemplo entonces no hablaríamos propiamente de tolerar a la anciana sino de ser equitativos con ella, a diferencia de la corrupción y abuso injustificables.

El respeto es un valor más claro, no admite medias tintas, parte del reconocimiento del otro, en su persona, ideas y acciones. No es que deba respetar a los demás "a veces" y/o "un poco", sino respetar de factum, sin redondeos. 
Ahora bien, respetar tampoco es aceptar todo sino velar por la integridad propia y de los demás; no es solo un valor estrictamente personal sino que se construye desde la intersubjetividad; y en este sentido el respeto es un valor ético-político porque se ejerce desde el reconocimiento de la alteridad.

Pero según MacCallum (1967), el respeto y la libertad quedan sólo en palabrerías si algún agente exógeno te domina, en su ensayo "Libertad positiva y libertad negativa" criticó los dos conceptos de libertad de Berlin para decir finalmente que solo hay un concepto de libertad: ausencia de dominación (respecto a los agentes, constricciones y fines). En sintonía, Shapiro (2012) considera que la libertad se alcanza desde la no-dominación: quien controle los recursos que la gente necesita para conseguir sus intereses básicos tendrá poder efectivo sobre esas personas y peor aún si tomamos en cuenta que la dominación puede ocurrir sin que haya órdenes explícitas de agentes identificables porque puede darse de forma involuntaria e inconsciente, incrustada en relaciones estructurales. Philip Pettit (1999) sería otro de los que considera que la libertad negativa consiste en la no-dominación, no en la no-interferencia. Personalmente me parece que estas lecturas de la "no-dominación" se pueden contrariar con relativa facilidad pues en cualquier contexto histórico siempre ha habido el disenso, personas o grupos que se rebelen, aún en contextos ultra represores como en las dictaduras o en los fanatismos. Dicho sea de paso, fueron estos ejemplos excepcionales los que justamente han hecho posible la historia... Las personas que han luchado por sus ideales, aun estando dominadas y en situaciones inmundas, sea Olympe de Gouges, Nelson Mandela, Luther King, Miguel Hernández, José Mujica o Malala Yousafzai, entre otros... No es demagogia subrayar que la historia de los derechos humanos ha avanzado gracias a la indignación y al disenso.

Además, ver a la libertad como no-dominación inevitablemente pasa por el filtro hermenéutico de la libertad interior de los dominados, recordemos el planteamiento oscuro que recupera Berlin de Mc Farlane: "conocer las propias cadenas es frecuentemente el primer paso para la libertad, que puede que no llegue nunca si se les ignora o se les ama" (Berlin, 1988, p.40). No será extraño entonces que haya Filosofías que lleguen a la libertad por otras vías... Schiller por ejemplo 
decía en la introducción a la Educación estética que "a la libertad se llega por la belleza" (Schiller, 1990, p. 101). Tal vez sea el hecho de que sólo el ánimo estético es capaz de desviar la ruta de la causalidad fría y objetiva. Berlin mismo reconoció que no sólo fue la historia sino el arte lo que le mostró el camino a la libertad; como lo deja ver su amistad con Pasternak, Brodsky y Anna Ajmátova. Berlin refirió alguna vez, que su relación con los poetas rusos le había modificado permanentemente su visión de la vida. Cuando Ajmátova le cuenta a Berlin (en ese encuentro que su biógrafo Michael Ignatieff (1999) refiere como único e inolvidable) de la ejecución de su marido, de la detención de su hijo, y de cómo todo esto había inspirado su poesía. De esta conversación que duró hasta al amanecer, Berlin supo ver en la voluntad de Anna como un ser humano puede superar el destino con la palabra y escapar a la alienación con la poesía... Anna revelaba la humanización del salvajismo bolchevique; tal vez fue ver en esta poeta rusa condenada al ostracismo la fortaleza ontológica para decir "no" a la resignación pasiva y crear espacios poéticos para realizar su autonomía. Así Berlin menciona en el Fuste torcido de la humanidad:

[...] la gloria y la dignidad del hombre se basan en el hecho de que es él el que elige y no eligen por él, de que puede ser su propio amo (aunque a veces esto le llene de temor y de una sensación de soledad), de que no está obligado a comprar seguridad y tranquilidad al precio de dejarse encerrar en un limpio casillero de una estructura totalitaria que pretende arrebatar la responsabilidad, la libertad y el respeto a uno mismo y a los demás, de un solo golpe (Berlin, 1992, p.190).

De Ajmátova quiero referir como la cultura estética concede la más completa autonomía a la voluntad individual, en cuanto que ésta sólo puede depender de ella misma. De las cosas que consigue la cultura estética es poner al hombre en situación de hacer por sí mismo lo que quiera, devolviéndole por completo la libertad insumisa, que bien invita a la dignidad.

La crítica de Berlin al determinismo histórico que se dejó ver en su magno estudio de la libertad positiva y negativa, seguramente fue enriquecido por lo que vio en Ajmátova: que la historia 
no predetermina las hermenéuticas subsecuentes, que un destino trágico también puede interpretarse estéticamente; pero para esto, haría falta un alma grande donde irrumpa la libertad.

Para Abril de 1948, a Berlin le advirtieron de la severa xenofobia contra los extranjeros en Moscú, y así es que canceló cualquier intento de visitar a Ajmátova. Además de que para 1952, Leo (tío de Isaiah) fuera detenido y acusado de pertenecer a una red de espías británicos entre los que figuraban su hermano Mendel y su sobrino Isaiah.

Todo esto no pudo mas que distanciar a Berlin del totalitarismo y acercarlo al liberalismo; le Ilevó a pugnar contra la estrechez mental de los que niegan el pluralismo. Para nuestro filósofo, cualquier sociedad o nación no es un mero término colectivo que represente a los individuos que posean ciertas características en común; los seres humanos han de ser más bien entidades independientes de la totalidad, que se reconocen no por una esencia universal sino en su existencia. Berlin apuesta por la libertad que se rebela a la cortina de hierro; discrepa, en fin, del cualquier fascismo político que pretenda imponer rutas únicas; desconfía de la seguridad y omnipotencia de verdades omnipotentes contra la riqueza infinita de lo que palpita y respira.

\section{¿Libertad ilimitada de la propiedad privada?}

Ahora entramos al ámbito de la libertad que más importancia tiene en el discurso neoliberal: el derecho a la propiedad privada. En este apartado no pretendo cuestionar este derecho sino más bien traer a la memoria una acotación planteada hace siglos por el liberalismo clásico: que el ejercicio de la propiedad privada, como de todas las libertades individuales no deben pasar por alto las libertades y derechos de los demás. En este sentido, la propiedad privada de ninguna forma debería justificar la trasgresión a las libertades y derechos de los trabajadores; en cuanto a jornadas, salarios y condiciones laborales. Y me parece que esto debería ser evidente para cualquier ciudadano, gobierno o partido político.

Locke decía que:

[...] cualquier cosa que se saca del estado en que la naturaleza la produjo y la dejó, y la modifica con su labor y añade a ella algo que es de sí mismo, es por consiguiente propiedad 
suya. [...] Porque este trabajo, al ser indudablemente propiedad del trabajador, da como resultado el que ningún hombre, excepto él, tenga derecho a lo que ha sido añadido a la cosa en cuestión, al menos cuando queden todavía suficientes bienes comunes para los demás (Locke, 2004, p. 10).

Y este último criterio es el que no se ve claro en las contradicciones del mundo neoliberal: el 33\% de la comida se pierde o se desperdicia en el "primer mundo", asimismo en el 2018 el 1\% de los ricos del mundo llegó a acumular el 82\% de la riqueza global (Hope, 2018), o lo que llegara a advertir el presidente del Banco Mundial, David Malpass (Wheatley, 2020) que cerca de 60 millones de personas caerán en la pobreza extrema a raíz de la pandemia del coronavirus. ¿Este nivel de desigualdad es justo o mínimamente decente? No veo forma de justificar filosóficamente un sistema económico-político donde un altísimo porcentaje de la población no tiene las necesidades básicas cubiertas mientras que un mínimo posee lo indecible... No obstante, pensadores como Milton Friedman (1980) o Friedrich von Kayek (entre otros liberales conservadores) apelarían a las ventajas de un sistema que permite el ejercicio ilimitado del derecho a la propiedad privada.

Locke más bien creía que el fundamento de la propiedad privada es el trabajo de cada hombre (Locke, 2004, p. 15). Y siguiendo esta línea, sería un agravio del estado neoliberal permitir salarios y patrimonios desorbitados que no van en proporción al trabajo de los beneficiarios. ¿Esto es correcto, justo o encomiable? La financiarización sería el más claro ejemplo de ello, la especulación financiera tiene más que ver con factores aleatorios que con el trabajo.

Aunque por otra parte, se podría pensar que a lo largo de historia la fuente de la riqueza no siempre ha sido el trabajo, a veces ha sido fruto del hurto, de la traición y de la avaricia y que incluso, esto forma parte de la naturaleza humana. Pero si reparamos en algunos datos antropológicos, no todas las culturas lo han visto así, algunas etnias ven como falta grave la excesiva acumulación de la riqueza, los Kapauku de Nueva Guinea por ejemplo, llegan a asesinar a los hombres egoístas y avaros, en esta tribu escogen a los jefes de la aldea y al "gran hombre" en función de su generosidad. Otra práctica que cuestiona el derecho a la acumulación ilimitada es el potlatch, sistema de intercambio de las tribus de las costas del Pacífico de Norteamérica y de los 
tsimshian de Alaska (Kotakk, 2010, pp. 196-7). Los patrocinadores del potlatch tradicionalmente regalan alimentos, mantas, piezas de cobre u otros artículos para conseguir prestigio. En el s. XIX por ejemplo, los kwaliutl comenzaron a comerciar con los europeos y aumentaron su riqueza pero también se contagiaron de enfermedades europeas por lo que se redujo la población y fue entonces que empezaron a destruir los artículos de riqueza como mantas, piezas de cobre y casas para evitar las grandes diferencias sociales y distanciarse de las tribus amigas. Como se ve entonces, en otras culturas la destrucción de riqueza da prestigio mientras que para la sociedad capitalista se vería menos que absurdo porque desde la "racionalidad capitalista" el objetivo es la plusvalía...

Thorsthein Veblen en su Teoría de la clase ociosa (1966) afirmó que el Potlatch se basaba en un impulso económicamente irracional en busca de prestigio. (p. 76). Pero si lo pensamos bien, tan irracional puede ser la búsqueda de prestigio como la especulación financiera virtual, la financiarización deviene en especulación sin sentido pues el mundo virtual de la economía es infinito... Quizá lo interesante del tema más bien sea plantear las consecuencias de ambos enfoques, no sólo en términos humanos sino ecológicos, problemáticas insoslayables del modo de producción capitalista y del consecuente consumismo. Cito algunos datos al respecto: antes del 2050 tendrían que reducirse las emisiones de gases de efecto invernadero entre un $40 \%$ y un $70 \%$ para evitar los peores efectos del cambio climático, según el Acuerdo de París; el $42 \%$ de los invertebrados terrestres se encuentran en riesgo de extinción y cada año, ocho millones de toneladas de plásticos acaban en los océanos (Sánchez y Planelles, 2019). ¿Esto es racional o inteligente? Me parece que de ninguna forma se podría justificar el uso y abuso de los recursos naturales y humanos que estamos haciendo, permitiendo o legitimando. No es demagogia, ni retórica evocar al uso responsable del derecho a la propiedad privada.

Otra de las cuestiones que salen a relucir en cuanto al neoliberalismo es el discurso hegemónico que reivindica la libertad en la mercadotecnia pero desde la racionalización de intereses económicos. La libertad del consumidor debería partir de la libertad del pensamiento, no de la manipulación. Pero clas enormes filas para comprar las últimas novedades en telecomunicaciones son realmente necesarias o son sólo racionalizaciones de la búsqueda de cierto 
estatus social? Vendría muy bien distinguir entre actuar conscientemente de actuar libremente porque una cosa es estar consciente d lo que hacemos sin percatarnos de la manipulación inconsciente de nuestra voluntad y otra cosa es ejercer el derecho a la propiedad privada desde la deliberación informada. La libertad interior es siempre el filtro hermenéutico por el que pasa cualquier información, de ahí que sea muy probablemente el único y efectivo recurso que nos quede para afrontar el poder de las élites empresariales y del marketing político y digital. Espero dejar ver que esta libertad del pensamiento es el nudo desde el cual se abre el perfil humanista, no es poca cosa; así volvemos al inicio de este trabajo, al planteamiento de la importancia de la libertad de pensar y asimismo de pensar en la libertad.

\section{Conclusión}

Pensar y repensar el sentido de los valores nunca es tiempo perdido, muy por el contrario, es el primer paso para la formación humanista. Y si lo humano es realmente valioso, único e irrepetible es en gran medida porque asumimos en uno mismo y en cualquier otro el derecho a ejercer su autonomía y su libertad. Pero la libertad puede devenir en relativismo que se legitima desde algunos enfoques posmodernos y/o posthumanistas, donde finalmente pareciera que todo es subjetivo; o bien la libertad puede devenir en individualismo rapaz como en el ideario neoliberal. En cualquiera de estas opciones no se vislumbran mejores mundos posibles...

No está demás poner en la mesa de debate ejes de análisis de las libertades negativas, sobre todo en lo que concierne a la libertad de expresión y de la propiedad privada. La libertad tal y como se planteaba desde el liberalismo clásico puede y debe ser compatible con la libertad de los demás. La libertad es compatible con el respeto, la justicia, la responsabilidad, la solidaridad y sobre todo con la esperanza; que dicho sea de paso, ahora más que nunca hay que construirla y esto sólo es posible desde el reconocimiento de la posibilidad de cambio, esto es, desde el reconocimiento de la libertad. Arendt citaba de Char: "a nuestra herencia no la precede ningún testamento" ${ }^{1}$ (Arendt, 1995, p. 75).

\footnotetext{
${ }^{1}$ Arendt, Hannah. “La brecha entre el pasado y el futuro" en De la historia a la acción. op. Cit., p. 75.
} 


\section{Referencias}

Arendt, H. (1995). De la historia a la acción. Barcelona: Paidós.

Arendt, H. (1999). Eichmann en Jerusalén, trad. Carlos Ribalta. Barcelona: Lumen.

Arendt, H. (2001). Hombres en tiempos de oscuridad. Barcelona: Gedisa.

Arendt, H. (2002). La vida del espíritu. Barcelona: Paidós.

Berlin, I. (1988). Cuatro ensayos sobre la libertad. Madrid: Alianza.

Berlin, I. (1992). Fuste torcido de la humanidad. Barcelona: Península.

Caballero, F. (28 de abril de 2015) elDiario.es https://www.eldiario.es/cultura/Charlie-Hebdodefensa-libertad expresion 0 382162050.html

Constant, B. (2002). Sobre la libertad en los antiguos y en los modernos. Madrid: Tecnos.

Friedman, M.; Friedman, R. (1980). Libertad de elegir: hacia un nuevo liberalismo económico. Barcelona: Grijalbo.

Gálvez, J. J. (23 de noviembre de 2018) Dani Mateo, imputado por sonarse con una bandera de España. El país. Polític. https://elpais.com/politica/2018/11/23/actualidad/1542980080 588311.html

Harvey, D. (2007). Breve historia del neoliberalismo. Madrid: Akal.

Hobbes, T. (2017). Leviatán. México: FCE.

Hope, K. (28 de enero de 2018) El 1\% de los ricos del mundo acumula el 82\% de la riqueza global (y las críticas a estas cifras de Oxfam). BBC News. Mundo.

https://www.bbc.com/mundo/noticias-42776299

Ignatieff, M. (1999). Isaiah Berlin:su vida. Madrid: Taurus.

Kotakk, C. P. (2010). Antropología cultural. México: McGraw Hill.

Lledó, E. (23 de noviembre de 2013) La verdadera crisis es la de la inteligencia. El español. Sociedad. https://diariodeavisos.elespanol.com/2013/11/emilio-Iledo-la-verdadera-crisis-esinteligencia/

Locke, J. (2004). Segundo ensayo sobre el gobierno civil. Madrid: Aliana.

MacCallum, G. (1967). Negative and Positive Freedom. The Philosophical Review, (76), pp. 312-334. 
Ordaz, P. (15 de enero de 2014) La Liga Norte redobla sus ataques racistas a la ministra Kyeng. El País. Internacional.

https://elpais.com/internacional/2014/01/15/actualidad/1389787662 383388.html

Pettit, P. (1999). La no dominación como ideal político. En: Republicanismo. Una teoría sobre la libertad y el gobierno. Barcelona: Paidós.

Popper, K. (2010) La sociedad abierta y sus enemigos. Barcelona: Paidós.

Rawls, J. (1995). Teoría de la justicia. México: FCE.

Sánchez, E. y Planelles, M. (13 de marzo 2019) La ONU pide cambios sin precedentes para evitar la catástrofe medioambiental del planeta. El País. Sociedad. https://elpais.com/sociedad/2019/03/12/actualidad/1552409167 549272.html

Shakur, A. (2013). Una autobiografía. trad. Ethel Odriozola, Carmen Valle, Madrid: Capitán Swing.

Shapiro, I. (2012). Elementos de la justicia democrática. Doxa. Cuadernos de Filosofía del Derecho, (35) 589-628.

Schiller, J. CH. F. (1990). Escritos sobre estética. Madrid: Tecnos.

Stuart, M. J. (2017). Sobre la libertad. Madrid: Edaf.

Veblen, T. (1966). Teoría de la clase ociosa. México:FCE.

Wheatley, J. (19 de mayo de 2020) Hasta 60 millones de personas caerán en la pobreza extrema. EI cronista. https://www.cronista.com/financialtimes/Hasta-60-millones-de-personas-caeranen-la-pobreza-extrema-20200519-0078.html 